\title{
Thyroid nodules with indeterminate cytology: is it safe to say 'thyroidectomy can be excluded if 18F-FDG-PET suggests benignity'?
}

\author{
Qi-Chang Wan'1 and Bin Ji(D)2 \\ 1Department of Nuclear Medicine, The Third Affiliated Hospital of Sun Yat-sen University, Guangzhou, China \\ 2Department of Nuclear Medicine, China-Japan Union Hospital of Jilin University, Changchun, China
}

Correspondence should be addressed to B Ji: jibin1983104@163.com

\section{Dear Editor,}

We read with interest the article by Rosario et al., published in the January 2021 issue of Endocrine-Related Cancer pages R1-R9, which summarized the practical applicability of accessible imaging method in the management of thyroid nodules with indeterminate cytology (TNIC) (Rosario et al. 2021). For ${ }^{18}$ F-FDG-PET, it was stated that 'a nodule characterized by low or absent ${ }^{18 F-F D G ~ u p t a k e ~}$ is considered at a very low risk of malignance', and 'thyroidectomy can be excluded if these tests suggest benignity'. We respectfully want to share a different opinion based on our previous work.

Hybrid ${ }^{18} \mathrm{~F}-\mathrm{FDG}$ PET/CT is the current state of the art and represents a more objective and accurate technique compared to ${ }^{18} \mathrm{~F}-\mathrm{FDG}$ PET alone. However, in our most recent meta-analysis, we found that the rule out performance of PET alone is significantly better than PET/CT (sensitivity, 0.95 vs 0.73 ; negative likelihood ratio, 0.20 vs 0.53 ; and negative predictive value, 0.99 vs 0.91) for TNIC (Qichang et al. 2020). This led us to the conclusion that ${ }^{18} \mathrm{~F}$-FDG PET alone is overvalued in the literature and future studies should be performed with 18F-FDG PET/CT. At the same time, we hypothesize that the lack of precise localization of suspicious FDG uptake in the neck region (physiological or pathological tracer uptakes from the tonsils, pharynx, cervical lymph nodes, and other thyroid nodules mistaken as being attributed to a malignant TNIC which in fact had no FDG accumulation) might have largely contributed to this overvaluation for PET alone studies.

For ${ }^{18 F-F D G ~ P E T / C T, ~ i t ~ i s ~ s t i l l ~ n o t ~ s a f e ~ t o ~ s a y ~}$ thyroidectomy can be excluded if it suggests benignity.
Our Fagan's nomogram indicated that when the pretest probability (prevalence of malignancy) was assumed to be $24 \%$, which is the median value of our included studies, the negative post-test probability decreased to $12 \%$ for a negative PET/CT scan. This is well above the risk of malignancy criteria for a cytology report to indicate benignity (<5\%) (Haugen et al. 2016).

Nevertheless, we hope that $18 \mathrm{~F}-\mathrm{FDG}$ PET/CT will be progressively gaining space in the management of patients with TNIC. Integrating PET features into existing individualized risk prediction models might help to spare a patient with benign TNIC from thyroidectomy. However, such studies have not been published as far as we know.

Declaration of interest

The authors declare that there is no conflict of interest that could be perceived as prejudicing the impartiality of this article.

\section{Funding}

This work did not receive any specific grant from any funding agency in the public, commercial or not-for-profit sector.

\section{References}

Haugen BR, Alexander EK, Bible KC, Doherty GM, Mandel SJ, Nikiforov YE, Pacini F, Randolph GW, Sawka AM, Schlumberger M, et al. 20162015 American Thyroid Association management guidelines for adult patients with thyroid nodules and differentiated thyroid cancer: the American Thyroid Association Guidelines Task
(C) 2021 Society for Endocrinology Published by Bioscientifica Ltd. Printed in Great Britain 
Force on Thyroid Nodules and Differentiated Thyroid Cancer. Thyroid 26 1-133. (https://doi.org/10.1089/thy.2015.0020)

Qichang W, Jinming S, Lu L, Bin J, Renjie W \& Xiuying Z 2020 Comparison of 18F-FDG-PET and 18F-FDG-PET/CT for the diagnostic performance in thyroid nodules with indeterminate cytology: a meta-analysis. Medicine 99 e20446. (https://doi.org/10.1097/ MD.0000000000020446)

Rosario PW, Rocha TG \& Mourão GF 2021 Usefulness of accessible imaging methods in thyroid nodules with indeterminate cytology. EndocrineRelated Cancer 28 R1-R9. (https://doi.org/10.1530/ERC-20-0326)

Received in final form 29 December 2020

Accepted 29 January 2021

Accepted Manuscript published online 19 February 2021 (c) 2021 Society for Endocrinology Published by Bioscientifica Ltd. Printed in Great Britain 